\title{
Effects of Androgen Deprivation by Castration on Cognitive Functions and Behaviors: A Review Study
}

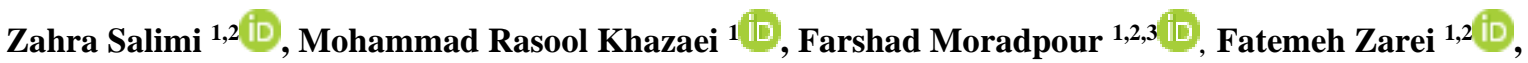 \\ Zahra Rashidi 1 (D), Seyed Mojtaba Ahmadi $1 *$ (D)
}

1. Fertility and Infertility Research Center, Health Technology Institute, Kermanshah University of Medical Sciences, Kermanshah, Iran

2. Dept. of Physiology, Kermanshah University of Medical Sciences, Kermanshah, Iran

3. Dept. of Biology, Centre for Biomedical Research, University of Victoria, Victoria, BC V8P 5C2, Canada

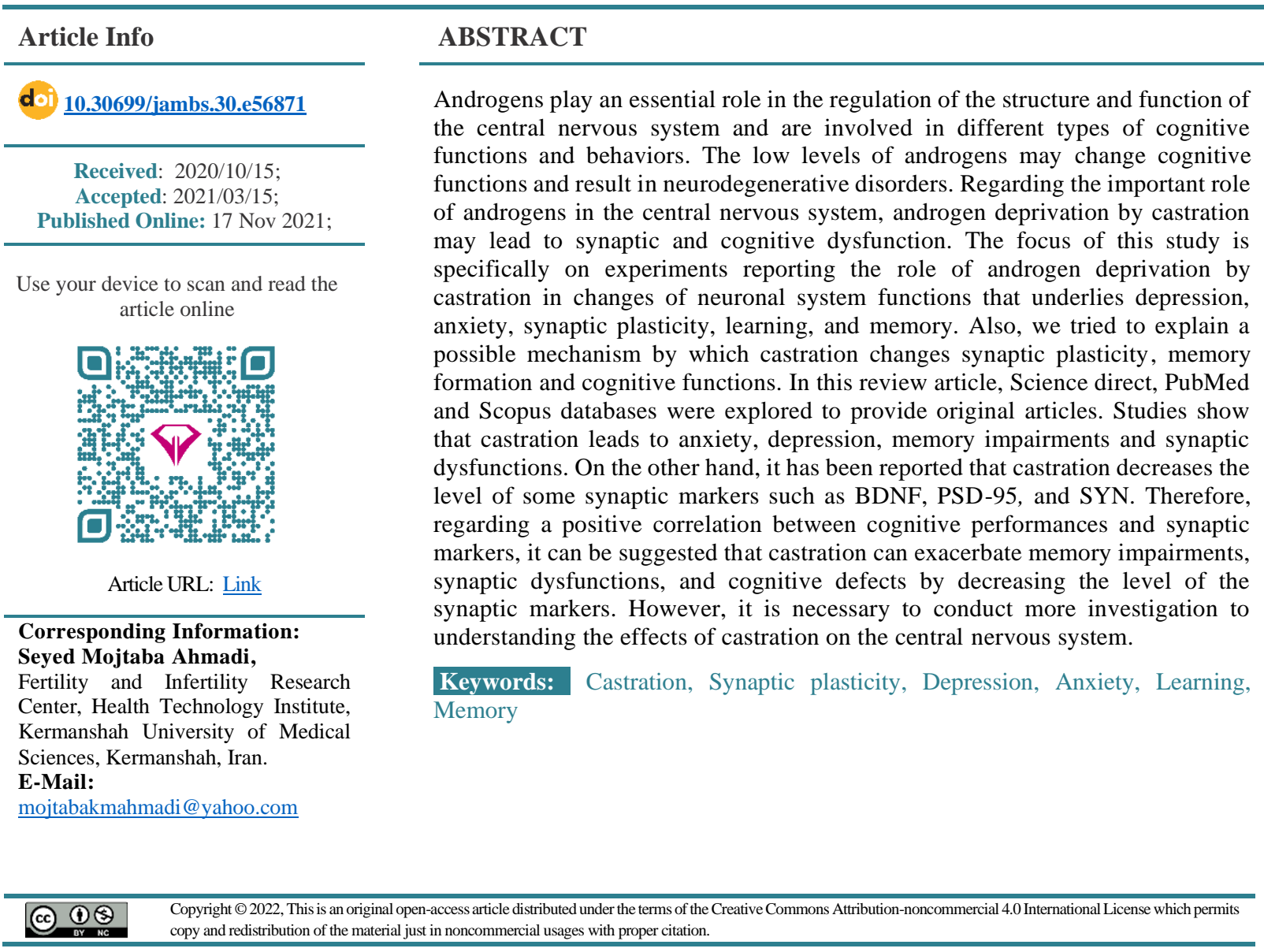

\section{Introduction}

Androgens have an essential role in some processes within the central nervous system (CNS), including the promotion of neuron growth, regeneration of axon, neurogenesis, protection against neuronal cell loss, induction of long-term synaptic plasticity, and many cognitive behaviors (1-2). It has been well established that intermediate levels of androgens are associated with better behavioral functions while their high and low levels impair cognitive performances (3-5). These results suggest that a remarkable decrease in androgen levels is related to significant change in cognitive functions and behaviors (6). Castration refers to any action, surgical or chemical, to eliminate the major source of sex hormones. Surgical castration is bilateral orchiectomy (removal of both testes), while chemical castration uses pharmaceutical drugs to deactivate the testes. In other words, castration significantly decreases the production of certain hormones, such as androgens (7). Concerning the important role of androgens in the CNS, androgen deprivation (suppressing or blocking the production or action of androgens) by castration can probably alter the cognitive functions and behaviors such as anxiety, depression, synaptic plasticity, learning, and memory. In this review article, the effect of castration on cognitive performances is first investigated. Finally, the possible molecular pathways involved in the modify of 
neuroplasticity, memory function, and cognitive behaviors will be discussed.

\section{Materials and Methods}

In this review article, Science direct, PubMed and Scopus databases were explored to provide original articles. Related original articles were investigated from 1939 to 2020 . After screening the published articles based on the title and abstract of the article, duplicate cases, articles that did not appropriate the purpose of this study and articles that only had abstract were removed.

\section{Results and Discussion}

\section{Effects of castration on synaptic plasticity:}

Hippocampus is one of the most important structures that mediates cognition, learning, memory, and mental behaviors. Long-term potentiation (LTP) in synaptic transmission was primary discovered in the hippocampus and has been considered as one of the molecular and cellular mechanisms of learning and memory $(8,9)$. Androgens play important roles in the regulation of the structure and function of the hippocampus. On the other hand, the abundance of androgenic receptors in the hippocampal CA1 area, might propose the action of androgens in the hippocampus to enhance synaptic plasticity (10). It has been well established that the dendrites integrate synaptic inputs to neuronal cells and their branching correlates to their representative capacity. Some research has revealed that spine morphology, spine density, and dendrite length can be affected by steroids in multiple brain areas involved in cognitive functions and behavior (11-14). Evidence from different studies reported that androgens increased the density of CA1 spine synapses (15) and neurogenesis of the hippocampus (16). Androgens can affect neural activities by raising the neuron growth, regeneration of axon and synaptic plasticity. In other words, androgens are strong facilitators of spine density and regulation of long-term potentiation in the brain $(17,18)$. The density of dendritic spine synapses of pyramidal cell in the hippocampal CA1 area is regulated by circulating androgens (15). These findings suggest that probably androgen deprivation by castration may alter the spine synapse density in the hippocampal CA1 area. The results of Leranth et al. are consistent with Moghadami et al. who exhibited that the castration reduced density of dendritic spines of the hippocampal CA1 area $(19,20)$. These structural modifications in dendrites may be responsible for the impairment of synaptic plasticity and memory functions. In support of these findings, some studies reported that castration significantly reduced the number of immature neurons in the hippocampus and spine density of medial preoptic nucleus neurons $(21,22)$. It has been well established that a moderate range of androgens is related to optimal brain functions and cognitive performances while their high and low levels are involved in memory impairment, synaptic dysfunction and cognitive defect (23-25). Regarding the important role of androgens in cognitive functions, it appears that the removal of androgens by castration can alternate synaptic plasticity and LTP induction in the hippocampal CA1 area. Therefore, in 2009, a study was carried out by Cooke et al. to evaluate this hypothesis. In their study, Whole-cell voltage clamp recordings made in slices from adult male rats revealed that castration declined the frequency of miniature excitatory postsynaptic currents in medial amygdala neurons (26). Overall, it could be concluded that androgens are positively associated with the structure and function of the CNS, while castration impairs synaptic plasticity by androgen deprivation. Thus, androgen deprivation is one of the most significant pathways for the impairment effects of castration on synaptic plasticity and neuroplasticity.

In a previous study, Moradpoure et al. (2013) investigated the effect of pre-pubertal castration on the neuronal response of pyramidal neurons of the hippocampal CA1 area. In their study for assessed the effects of elimination of the major source of male sex hormones on CA1 synaptic plasticity, animals were castrated at the age of 22 days and synaptic transmission and plasticity in the hippocampal CA1 area were examined. According to their results, pre-pubertal castration (at the age of 22 days) had no effect on the magnitude of fEPSP-LTP and PS-LTP at 28 and 45 days in male rats (27). On the other hand, Lee et al. showed that the serum androgens level during pre and midadolescence was lower than post-adolescence and it gradually increased to adult levels (28). Regarding the low level of androgens during pre and mid-adolescence, it could be assumed that castration does not affect synaptic plasticity during these periods. In support of this idea, in a recent study, Salimi et al. (2020) examined the effect of castration on the neuronal response of pyramidal neurons of the hippocampal CA1 area during adolescence. Their findings showed that castration did not affect the magnitude of fEPSP-LTP and PS-LTP during midadolescence (5). The androgen level during pre and midadolescence was lower than the post-adolescence, hence, the elimination of a low level of androgens during these periods does not affect synaptic plasticity (5). These investigations suggested that androgen deprivation by castration could have different effects on hippocampal function during different periods of life.

The induction of LTP is related to the activation of many molecules and signaling cascades. PSD-95 is one of the most abundant proteins of the postsynaptic density that regulates diverse forms of synaptic transmission, synapse structure and stability along with formation and long-term stabilization of memory (29-32). It is well established that PSD-95-dependent protein complexes interact with NMDA and AMPA-type glutamate receptors (33). Interactions between PSD-95 and the NMDA receptor in the postsynaptic density are essential for synaptic plasticity (34). Therefore, PSD-95 dysfunction may change synaptic plasticity actions in the dendritic spines that contribute to the defects of the synapse-associated with neurological disorders. In a 
previous study, Migaud et al. investigated the effect of the PSD knockouts on spatial localization in male mice. The first behavioral characterization of mice PSD knockouts slowed robust impairment of spatial memory (35). Most of the published articles have declared that PSD-95 is strongly regulated by androgens $(30,36,37)$. Therefore, androgen deprivation due to castration can change the PSD-95 level. In 2012, Yoshii et al. investigated the effect of castration on the level of PSD-95. According to their results, PSD-95 was reduced from one week and lasted to 4 weeks after castration (38). These findings suggested that a decrease in PSD-95 level could be one of the pathways underlying the cognitive disrupting effects of castration.

Furthermore, Brain-derived neurotrophic factor (BDNF) is another critical molecule involved in synaptic plasticity processes. BDNF-TrkB signaling plays a key role in synaptic development by regulating the post-synaptic density protein PSD-95 (39). Evidence from different studies suggests that BDNF is a potential mediator for the central influences of androgens (40-42). On the other hand, some studies have reported the transcription of BDNF mRNA modulates by gonadal steroids $(41,42)$. According to some findings of the regulation of BNDF by androgens, there is a potential relationship between androgens and BDNF. Therefore, it can be hypothesized the elimination of the major source of androgens by castration could have a negative effect on BDNF. This hypothesis was explored in previous studies and it was revealed that castration declined
BDNF mRNA and protein expression $(42,43)$. Therefore, reduced BDNF level due to androgen deprivation by castration plays an important role in synaptic dysfunction, memory impairment (44) and the pathogenesis of numerous neuropsychiatric disorders (45). To sum up, it appears that the low BDNF and PSD-95 levels by castration may be responsible for neuroplasticity and synaptic dysfunctions.

Emerging evidence suggests that in addition to PSD95 and BDNF, synaptophysin (SYN) is also a critical factor in the neuroplasticity and LTP induction. Wei et al. also reported that decreased SYN expression in the hippocampus could lead to neuroplasticity impairments in the hippocampus (46). Therefore, it is conceivable that the promotion in SYN enhanced NMDA receptor formation, causing an improvement in synaptic plasticity.

Androgens increase synaptic markers (BDNF, PSD95 and SYN), modulate the essential biology of synaptic structure, and cause the structural changes of plasticity in the hippocampus, all of that lead to improve cognitive function (Fig. 1).

Some studies have reported a significant decline in the expression of the synaptic proteins and markers (SYN and CREB) after castration (47-49). Regarding the prominent roles of BDNF, PSD-95, and SYN in neuronal morphology, neuroplasticity, and synaptic plasticity, it seems that castration can exacerbate synaptic plasticity impairment and its related deficits by decreasing the level of these proteins and markers (Fig. 2).

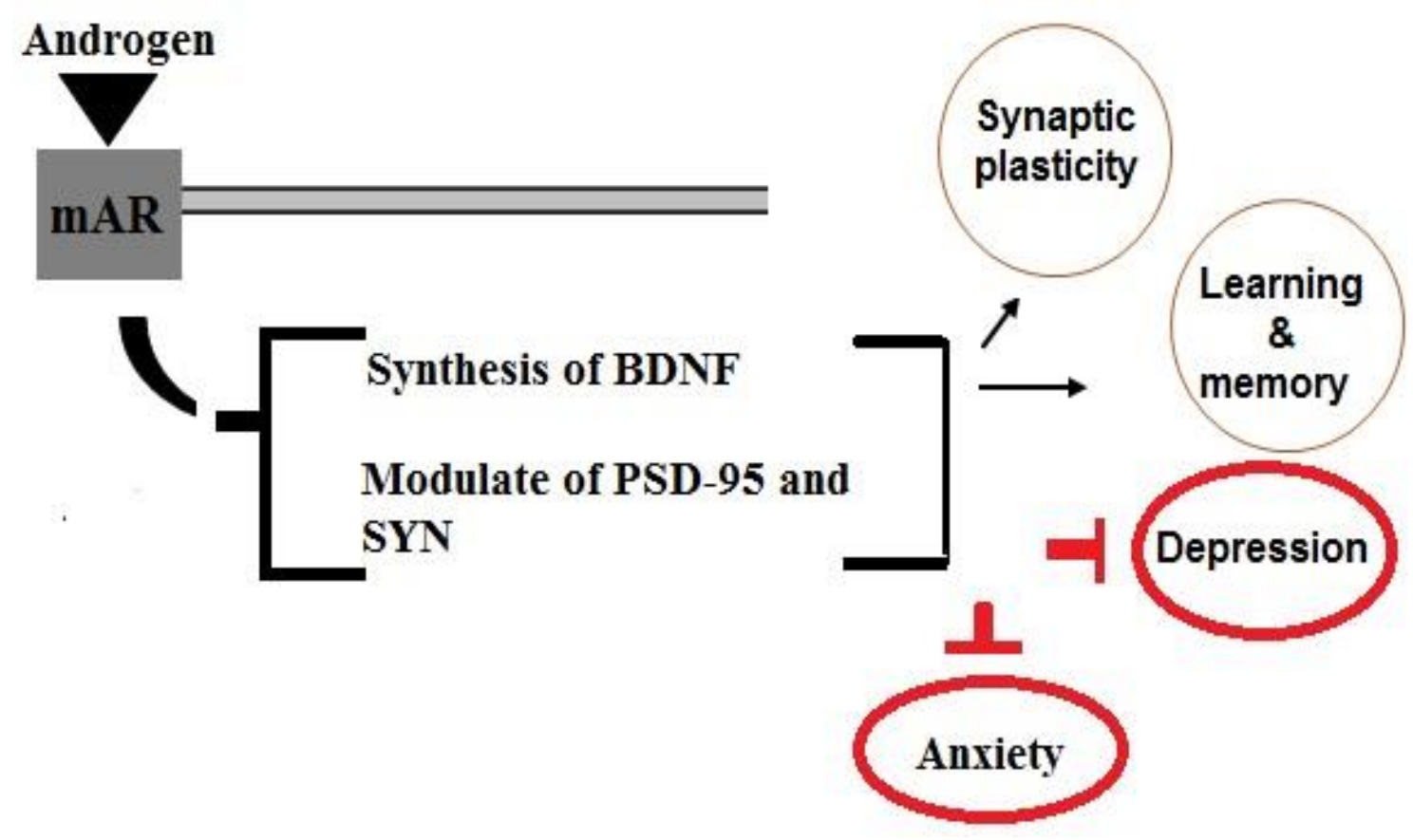

Figure 1: Schematic representation of a possible relationship between androgens and synaptic markers. Binding of androgens to membrane androgenic receptors improves cognitive functions by activating BDNF synthesis and regulating PSD-95 and SYN levels. 


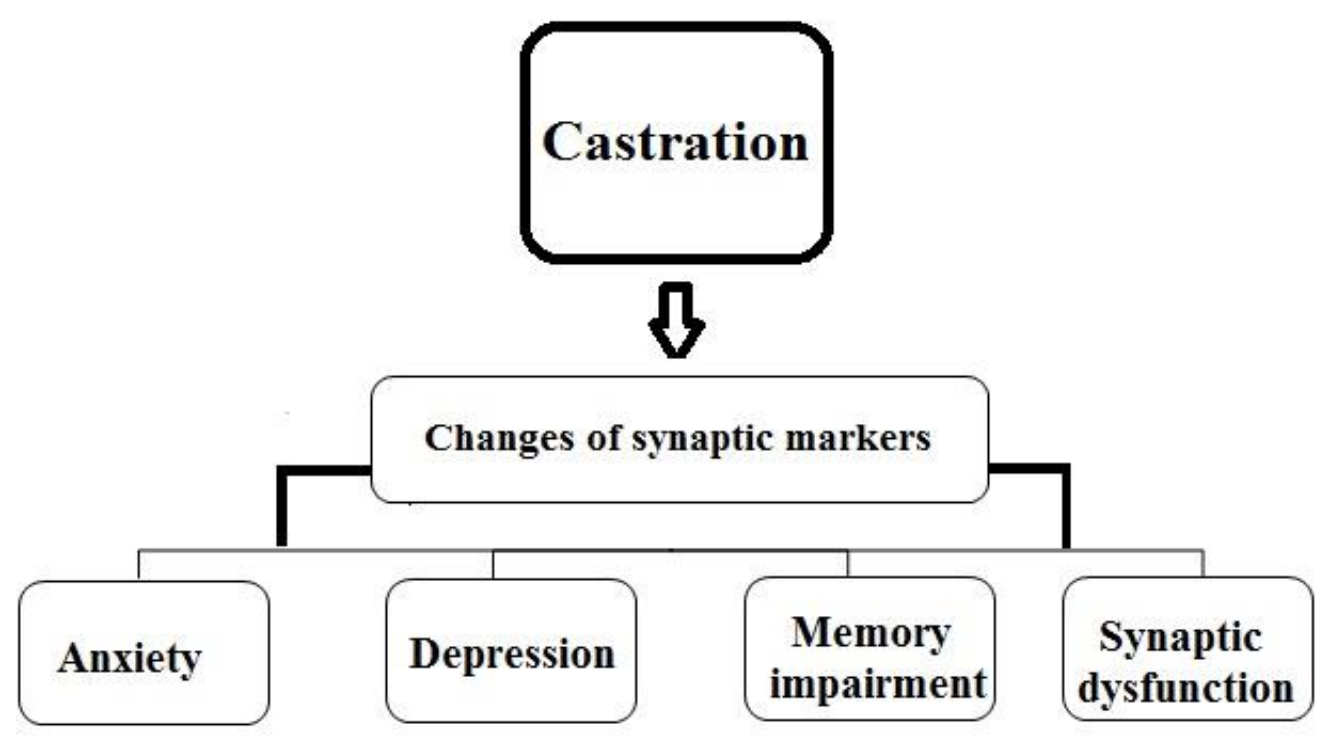

Figure 2: Diagrammatic representation of a possible relationship between castration and cognitive defects. Castration through changes in synaptic markers and proteins leads to memory impairment, synaptic dysfunction and other cognitive defects.

\section{Effects of castration on learning and memory}

Learning and memory are two important closely related cognitive processes in the CNS that are dependent on synaptic plasticity. Numerous investigations have addressed the roles of androgens in mediating and/or modulating spatial localization and also the different types of learning and memory performances (3-5). To survive, animals develop fear reactions to unsafe situations. The neural mechanism of learned fear has survival importance for animals that must estimate danger from seemingly neutral contexts. It has been documented that contextual fear conditioning is perhaps the simplest type of learning from an operational perspective. On the other hand, it has been well established that androgens affect learning processes related to approach/avoidance behaviors (15). Therefore, performance in inhibitory avoidance is influenced by androgen deprivation. A previous study reported that the castrated male rodents exhibit poorer performance in inhibitory avoidance (50). Spatial learning and memory describe the capability to encode, storage and retrieval of knowledge about the position of environmental properties relative to each other and the individual. Additionally, many evidences confirm that spatial performance in Y-maze and Morris water maze tasks are dependent upon the integrity of the hippocampus and are affected by androgen (50-52). Therefore, decline in androgens levels can influence various cognitive performances such as learning and memory (6). Some studies suggested the negative correlation between castration and memory functions. In line with these results, Moghadami et al. reported that the castrated male rats needed more time to find the hidden platform than the intact rats, indicating that castration impairs spatial learning and memory of adult male rats (20). In 2010, Benice et al. added further evidence on the relationship between androgens and spatial learning and memory.
According to their results, castration-induced androgen deprivation in mice impairs spatial localization (21). Overall, androgen deprivation is one of the most important reasons for the impairment effects of castration on learning and memory performances.

Working memory is explained as a form of short-term memory which includes storage of information from a specific task for as long as it is beneficial to complete the task, and reference memory is explained as the long-term storage of information that is used from one task to the next $(\mathbf{5 3}, \mathbf{5 4})$. Some studies have suggested that androgen depletion by castration impairs spatial working memory but has no effect on the reference memory of adult male rats $(16,55)$. Therefore, the above findings illustrate that androgen deprivation differentially affects the working and reference components of learning and memory.

Some studies exist for no effect of castration on learning and memory. In line with this evidence, Salimi et al. investigated the effect of castration on spatial learning and memory during adolescence of male rats in Morris water maze test. They reported that castration during adolescence had no effect on spatial performance (5). These findings suggest that castration during adolescence does not affect spatial localization ability, while castration in adult male rats led to impairment of spatial learning and memory.

Besides, SYN levels have been used as an index of synaptic density and distribution and are positively associated with cognitive functions in rodents (56-58). Previous studies have proposed the involvement of SYN in learning and memory functions. For example, heat stress-induced memory deficiency in Y-maze tasks is associated with a declined level of SYN expression in the hippocampus (59). Furthermore, some reports on the reduced expression of SYN after castration (44), proposed 
castration induced impairment of learning and memory performances through the change of SYN level.

On the other hand, it has been well established that the strong influence of BDNF on synaptic learning and memory processes is regulated by androgens, indicating a potential relationship between androgens and BDNF $(41,42)$. A great number of studies have revealed that decreased BDNF level is associated with the impairment of learning and memory (44). Interestingly it was reported that castration declined BDNF mRNA and protein $(42,43)$. Based on these findings, another possible pathway for the negative effects of castration on learning and memory could be the decrease of BDNF level.

Overall, it can be concluded that as the level of androgens varies in different periods of life, androgen deprivation by castration may have different effects on learning and memory functions at different stages of life. Regarding the low levels of androgens during pre and mid-adolescence, androgen deprivation by castration has no significant effect on learning and memory performances during these periods, while castration during post-adolescence and in adults can significantly impair learning and memory functions. Furthermore, some reports suggested a close relationship between synaptic markers (SYN and BDNF) and cognition functions such as learning and memory, thus, androgen deprivation by castration might lead to learning and memory impairment by decreasing the levels of SYN and BDNF.

\section{Effects of castration on anxiety and depression}

Depression and anxiety are recognized as the most common psychiatric disorders that have a profound impact on functioning and quality of life (24). Androgens are protective against the progression and development of cognitive disorders. Changes in gonadal androgen levels over the time of life lead to the alternation in cognitive performances and different types of psychiatric disorders $(24,60)$. Some evidence suggests that the physiological levels of androgens play a protective role against psychiatric disorders, while low levels of androgens are implicated in the status and severity of psychiatric disorders $(\mathbf{2 4 , 2 5 )}$. In support of this idea, Veras et al. and Cooper et al. report that hypogonadal patients, who suffer from lower than normal levels of androgens, are more likely to suffer from depression and anxiety disorders $(61,62)$. On the other hand, evidence from different studies suggests that androgens have anxiolytic and antidepressant effects, with the potential to promote improved mood and mental health $(24,60)$. Therefore, it appears that androgen deprivation by castration may lead to depression and anxiety-like behavior. Consistent with such a hypothesis, Almeida et al. have reported that castration is associated with increased depression and anxiety. (6). Furthermore, Boivin et al. propose that testicular hormones have anxiolytic impacts during puberty. The anxiolytic influences of testicular hormones during puberty may be critical for promoting the approach/exploratory behaviors important for foraging and navigating the transition to adult cognition behaviors. Also, castrated males showed more anxiety-related behavior than intact males (63). This evidence declares that an optimum level of androgens induced anxiolytic effects. Furthermore, it has been well established that androgens had antidepressant impacts on humans and animals. Interestingly, hypogonadal men with low levels of androgens have an increased incidence of major depressive disorder and androgens replacement significantly improved this psychiatric disorder $(64,65)$. Some previous studies reported that androgens supplementation had anxiolytic and antidepressant effects in castrated male rats $(\mathbf{2 4 , 6 0 )}$. These findings suggest a significant role for androgens in mediating anxiolytic and antidepressant effects. On the other hand, abnormalities in the regulation of neurotransmitters systems (e.g. serotoninergic and dopaminergic systems) can lead to anxiety and depressive-like behavior (25, 66). Concerning anxiety and depression, androgens exert modulatory impacts on several monoaminergic neurotransmitters, including dopamine and serotonin (5HT), which may protect against anxiety and depression $(24,67)$. A large number of studies suggest that androgens increase the uptake and production of serotonin (5-HT) and up regulate 5-HT receptors. (68). A study conducted by Huijgens et al. reported that castration decreased the release of neurotransmitter of dopamine (22). Interestingly, extensive literature confirms that BDNF regulates dopaminergic, serotonergic and noradrenergic activity $(69,70)$. Moreover, it has been well established that BDNF pathway impairment may be involved in the status and severity of psychiatric disorders such as depression and anxiety $(71,72)$. On the other hand, it is reported that subcutaneous injections of BDNF produced antidepressant and anxiolytic-like impacts in rodents (73,74). As we mentioned previously, BDNF may be a major target of androgen/ARs actions. It is important to understand the influence of androgens/ARs/BDNF on neurobiological systems that regulate depression and anxiety-like behavior. Therefore, it appears that castration (androgen deprivation) through decreased BDNF levels is involved in the abnormalities of neurotransmitters systems activity (e.g. serotoninergic and dopaminergic systems) that may be responsible for synaptic and cognitive dysfunctions. Consistent with these findings, some studies have reported that castration decreases BDNF mRNA and protein expression $(42,43)$. It can be assumed that castration leads to decrease in BDNF levels, which can be considered as a potential pathway to the status and severity of depression and anxiety-like behaviors. In addition, there is also extensive literature on the existence of the relationship between PSD-95 and androgens (48). Most published articles have declared that PSD-95 is strongly regulated by androgens and interaction with serotonin receptors 5- HT (2A) and 5- HT (2C) (75). In a previous study, castration was shown to reduce PSD-95 starting at one week and lasting up to 4 weeks after castration (38). On the other hand, it is established that the dysfunction of PSD-95 is implicated in depression and anxiety-like behavior $(76,77)$. In conclusion, it seems likely that the decrease of PSD-95 by castration (androgen deprivation) is responsible for cognitive dysfunctions such as depression and anxiety. In 
addition, it is well established that SYN plays the main role in neurotransmitter release and the synaptic vesicle cycle. Recent research have suggested that reduced SYN level is implicated in anxiety behavior and cognitive impairments $(73,78)$. For example, mice with traumatic brain injury display increased anxiety-like behavior and reduced SYN levels in the hippocampus (79). Moreover, in a previous study, the expression of SYP was increased in the hippocampus and the cortex by chronic antidepressant treatment in rats (80-82). The decreased expression of SYN after castration suggests that another possible pathway for the negative effects of castration on cognitive functions such as depression and anxiety is mediated by reducing the level of SYN. Overall, regarding the implication of synaptic markers and proteins (BDNF, PSD-95 and SYN) in cognitive functions and behaviors, it can be argued that castration leads to the progression and development of numerous cognitive disorders such as anxiety and depression-like behavior through decreasing the level of these biomarkers.

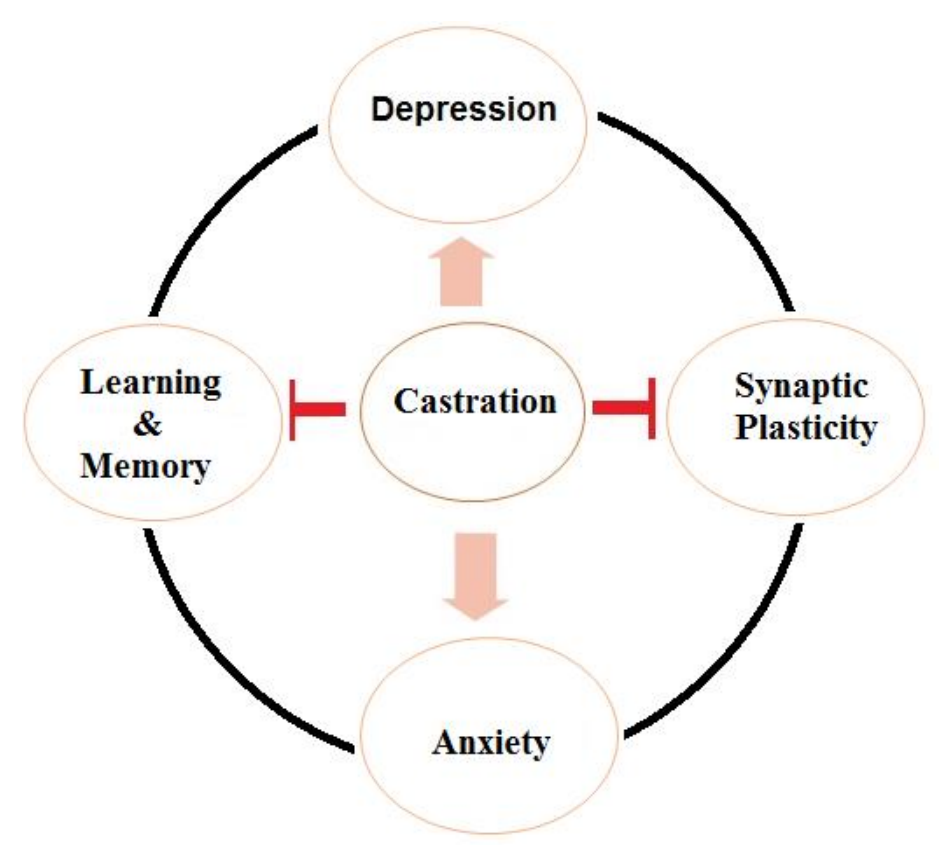

Figure 3: Possible central effects of castration

\section{Conclusion}

Androgens have profound effects on the neuronal organization, structure, and function of the brain including alternation in the spine synapses of neurons, neurogenesis, induction of long-term synaptic plasticity, and different type of cognitive functions and behaviors. Regarding the important role of androgens in the CNS, androgen deprivation by castration may lead to synaptic impairments and cognitive dysfunctions. In this review article, the emphasis was on studies addressing the effect of castration on neuroplasticity, memory functions and behavioral cognitions. The results agree with the fact that castration can change learning, memory, synaptic plasticity, anxiety, and depression, a graphical representation is reported in Fig. 3. Some of these effects on neuronal function may be due to a decrement in androgens levels which occurs by castration. On the other hand, it has been reported that androgens regulate the levels of synaptic markers (BDNF, PSD-95 and SYN), modulate the essential biology of synaptic structure, and cause structural alternations of plasticity in the hippocampus, all of which can improve cognitive functions. Regarding a close relationship between these synaptic markers and androgens, it appears that a reduction in these synaptic markers level through castration-induced androgen deprivation may be responsible for memory impairments, synaptic dysfunctions and cognitive defects. Taken together, the effects of castration (androgen deprivation) on the CNS can help to identify cognitive disorders and related pathways in male hypogonadism or people who suffer from gonadal dysfunction and also may help in the development of better therapeutic approaches to reduce these cognitive disorders.

\section{Acknowledgment}

The authors would like to acknowledge the Kermanshah University of Medical Sciences to support this work.

\section{Conflicts of Interest}

There is no conflict of interest. 


\section{References}

1. Spear LP. The adolescent brain and age-related behavioral manifestations. Neurosci Biobehav Rev. 2000;24:417-463. [DOI:10.1016/S01497634(00)00014-2]

2. MacLusky N, Hajszan T, Prange-Kiel J, Leranth C. Androgen modulation of hippocampal synaptic plasticity. Neurosci. 2006;138:957-65. [DOI:10.1016/j.neuroscience.2005.12.054] [PMID]

3. Janowsky JS, Oviatt SK, OrwoJll ES. Testosterone influences spatial cognition in older men. Behav Neurosci. 1994;108:325-32. [DOI:10.1037/07357044.108.2.325] [PMID]

4. Babanejad S, Naghdi N, HaeriRohani SA. Microinjection of dihydrotestosterone as a 5alpha reduced metabolite of testosterone into $\mathrm{CA} 1$ region of hippocampus could improve spatial learning in the adult male rats. Iran J Pharm Res. 2012;11:66169.

5. Salimi Z, Khajehpour L, Moradpour F, Moazedi, AA, Pourmotabbed, A, Zarei F. Nandrolone improve synaptic plasticity at the hippocampus CA1 area and spatial localization in the Morris water maze of male adolescent rats. Neurosci Res. 2020;158:21-29.

[DOI:10.1016/j.neures.2019.09.001] [PMID]

6. Almeida O, Waterreus A, Spry N, Flicker L, Martins RN. One year follow-up study of the association between chemical castration, sex hormones,beta-amyloid, memory and depression in men, Psychoneuroendocrinology. 2004;29:1071-1081.

[DOI:10.1016/j.psyneuen.2003.11.002] [PMID]

7. Mccullagh EP. The effects of castration in the adult male. JAMA. 1934;103(15):1140. [DOI:10.1001/jama.1934.02750410030006]

8. Bliss TV, Collingridge GL. A synaptic model of memory: long-term potentiation in the hippocampus. Nature. 1993;361(6407):31-9. [DOI:10.1038/361031a0] [PMID]

9. Abel T, Lattal KM. Molecular mechanisms of memory acquisition, consolidation and retrieval. Curr Opin Neurobiol. 2001;11(2):180-7. [DOI:10.1016/S0959-4388(00)00194-X]

10. Kerr JE, Allore RJ, Beck SE, Handa RJ. Distribution and hormonal regulation of androgen receptor (AR) and AR messenger RNA in the rat hippocampus. Endocrinol. 1995; 13:3213-21. [DOI:10.1210/endo.136.8.7628354] [PMID]

11. Beltran-Campos V, Prado-Alcala RA, LeonJacinto U, Aguilar-Vazquez A, Quirarte GL, Ramirez-Amaya V, Diaz-Cintra S. Increase of mushroom spine density in CA1 apical dendrites produced by water maze training is prevented by ovariectomy. Brain Res. 2011;1369:119-130. [DOI:10.1016/j.brainres.2010.10.105] [PMID]

12. Wu WW, Adelman JP, Maylie J. Ovarian hormone deficiency reduces intrinsic excitability and abolishes acute estrogen sensi tivity in hippocampal CA1 pyramidal neurons. J Neurosci. 2011; 31:2638-2648.

[DOI:10.1523/JNEUROSCI.6081-10.2011] [PMID] [PMCID]

13. Cunningham RL, Claiborne BJ, McGinnis MY. Pubertal exposure to anabolic androgenic steroids increases spine densities on neurons in the limbic system of male rats. Neurosci. 2007;150: 609-615. [DOI:10.1016/j.neuroscience.2007.09.038] [PMID] [PMCID]

14. Peterson BM, Mermelstein PG, Meisel RL. Estradiol mediates dendritic spine plasticity in the nucleus accumbens core through activation of mGluR5. Brain Struct Funct. 2015; 220: 24152422. [DOI:10.1007/s00429-014-0794-9] [PMID] [PMCID]

15. Edinger KL, Frye CA. Intrahippocampal administration of an androgen receptor antagonist, flutamide, can increase anxiety-like behavior in intact and DHT-replaced male rats. Horm Behav. 2006;50:216-222.

[DOI:10.1016/j.yhbeh.2006.03.003] [PMID]

16. Spritzer MD, Galea LA. Testosterone and dihydrotestosterone, but not estradiol, enhance survival of new hippocampal neurons in adult male rats. Dev Neurobiol. 2007;67:1321-1333. [DOI:10.1002/dneu.20457] [PMID]

17. Lynch MA. Long-term potentiation and memory. Physiol Rev. 2004; 84:87-136. [DOI:10.1152/physrev.00014.2003] [PMID]

18. Magnusson K, Bazov I, Clausen F, Zhou Q. Nandrolone decanoate administration elevates hippocampal prodynorphin mRNA expression and impairs Morris water maze performance in male rats. Neurosci Lett. 2009;467:189-93. [DOI:10.1016/j.neulet.2009.09.041] [PMID]

19. Leranth C, Petnehazy O, MacLusky NJ. Gonadal hormones affect spine synaptic density in the CA1 hippocampal subfield of male rats. J Neurosci. 2003;23:1588-1592.

[DOI:10.1523/JNEUROSCI.23-05-01588.2003] [PMID] [PMCID]

20. Moghadami S, Jahanshahi1 M, Sepehri H, Amin $\mathrm{H}$. Gonadectomy reduces the density of androgen receptor-immunoreactive neurons in male rat's hippocampus: testosterone replacement compensates it. Behav Brain Funct. 2016;12:1-10. [DOI:10.1186/s12993-016-0089-9] [PMID] [PMCID] 
21. Benice T, Raber J. Castration and training in a spatial task alter the number of immature neurons in the hippocampus of male mice. Brain Res. 2010;21-29. [PMID] [PMCID] [DOI:10.1016/j.brainres.2010.03.028]

22. Huijgens PT, Snoeren E, Meisel RL, Mermelstein PG. Effects of gonadectomy and androgen on neuronal plasticity in motivation and reward related brain regions in the male rat. Cold Spring Harbor Laborary. 2020; 1-12. [DOI:10.1111/jne.12918] [PMID]

23. Filova B, Ostatnikova D, Celec P, Hodosy J. The effect of testosterone on the formation of brain structures. Cells Tissues Organs. 2013;197;169177. [DOI:10.1159/000345567] [PMID]

24. McHenry J, Carrier N, Hull E, Kabbaj M. Sex Differences in Anxiety and Depression: Role of Testosterone. Front Neuroendocrinol. 2014; 35(1): 42-57. [PMID] [PMCID]

[DOI:10.1016/j.yfrne.2013.09.001]

25. Tamatam A. Genetic biomarkers of depression Indian J Hum Genet. 2012;18:20-33. [DOI:10.4103/0971-6866.96639] [PMID] [PMCID]

26. Cooke BM, Woolley CS. Effects of prepubertal gonadectomy on a male-typical behavior and excitatory synaptic transmission in the amygdala. Dev Neurobiol. 2009;1-18.

27. Moradpour F, Fathollahi Y, Naghdi N, Hosseinmardi N, Javan M. Prepubertal castration causes the age-dependent changes in hippocampal long-term potentiation. Synapse. 2013;67:235-44. [DOI:10.1002/syn.21636] [PMID]

28. Lee VW, Kretser DM, Hudson B, Wang C. Variations in serum FSH ,LH and testosterone levels in male rats from birth to sexual maturity. $\mathrm{J}$ Reprod Fertil. 1975;42(1):121-6. [DOI:10.1530/jrf.0.0420121] [PMID]

29. Ehrlich I, Klein M, Rumpel S, Malinow R. PSD95 is required for activity-driven synapse stabilization. Proc Natl Acad Sci. 2007;104:41764181. [DOI:10.1073/pnas.0609307104] [PMID] [PMCID]

30. El-Husseini A, Schnell E, Chetkovich D. PSD-95 involvement in maturation of 405 excitatory synapses. Science. 2000;290:1364-8.

31. Elias GM, Elias L, Apostolides PF, Kriegstein AR, Nicoll RA. Differential trafficking of AMPA and NMDA receptors by SAP102 and PSD-95 underlies synapse development. Proc Natl Acad Sci USA. 2008;105:20953-20958. [DOI:10.1073/pnas.0811025106] [PMCID]

[PMID]

32. Nikonenko I. PSD-95 promotes synaptogenesis and multiinnervated spine formation through nitric oxide signaling. J. Cell Biol. 2008;183:1115-27. [DOI:10.1083/jcb.200805132] [PMID] [PMCID]

33. Opazo P, Sainlos M, Choquet D. Regulation of AMPA receptor surface diffusion by 438 PSD-95 slots. Curr Opin Neurobiol. 2012;22:453-460. [DOI:10.1016/i.conb.2011.10.010] [PMID]

34. Hata Y, Takei Y. Roles of postsynaptic density95/synapse-associated protein 90 and its interacting proteins in the organization of synapses. Cell Mol Life Sci. 1999;56:461-472. [DOI:10.1007/s000180050445] [PMID]

35. Migaud M, Charlesworth P, Dempster M, Webster LC, Watabe AM, Makhinson M, et al. Enhanced long-term potentiation and impaired learning in mice with mutant postsynaptic density-95 protein. Nature. 1998;396:433-439. [DOI:10.1038/24790] [PMID]

36. Kretz O, Fester L, Wehrenberg U, Zhou L, Brauckmann S, Zhao S, Prange-Kiel J, Naumann T, Jarry H, Frotscher M, Rune GM. Hippocampal synapses depend on hippocampal estrogen synthesis. J Neurosci. 2004;24:5913-5921. [DOI:10.1523/JNEUROSCI.5186-03.2004] [PMID] [PMCID]

37. Liu F, Day M, Muniz LC, Bitran D, Arias R, Revilla-Sanchez R, Grauer S, Zhang G, Kelley C, Pulito V, Sung A, Mervis RF, Navarra R, Hirst WD, Reinhart PH, Marquis KL, Moss SJ, Pangalos MN, Brandon NJ. Activation of estrogen receptorbeta regulates hippocampal synaptic plasticity and improves memory. Nat Neurosci. 2008;11:334343. [DOI:10.1038/nn2057] [PMID]

38. Yoshii A, Constantine-Paton M. BDNF induces transport of PSD-95 to dendrites through PI3KAKT signaling after NMDA receptor activation. Nat Neurosci. 2007;10:702-711. [DOI:10.1038/nn1903] [PMID]

39. Sohrabji F, Miranda RC, Toran-Allerand C.D. Identification of a putative estrogen response element in the gene coding for BDNF. Proc Natl Acad Sci USA. 1995;92:11110-11114.

[DOI:10.1073/pnas.92.24.11110] [PMCID]

40. Osborne MC, Verhovshek T, Sengelaub DR. Androgen regulates trkB immunolabeling in spinal motoneurons. J. Neurosci. Res. 2007;85:303-309. [DOI:10.1002/jnr.21122] [PMID]

41. Ottem EN, Beck LA, Jordan CL, Breedlove SM. Androgendependent regulation of brain-derived neurotrophic factor and tyrosine kinase $\mathrm{B}$ in the sexually dimorphic spinal nucleus of the bulbocavernosus. Endocrinol. 2007;148:36553665. [DOI:10.1210/en.2007-0308] [PMID]

42. Verhovshek T, Cai Y, Sengelaub R. Androgen Regulates Brain-Derived Neurotrophic Factor in Spinal Motoneurons and Their Target 
Musculature. Endocrinol. 2010;151(1):253-261. [DOI:10.1210/en.2009-1036] [PMID] [PMCID]

43. Heldt SA, Stanek L, Chhatwal JP, Ressler KJ. Hippocampus-specific deletion of BDNF in adult mice impairs spatial memory and extinction of aversive memories. Mol Psychiatry. 2007;12:65670. [DOI:10.1038/sj.mp.4001957] [PMID] [PMCID]

44. Yang Y, Liu Y, Wang G, Hei G, Wang X, Li R, Li $\mathrm{L}$, Wu R, Zhao J. Brainderived neurotrophic factor is associated with cognitive impairments in firstepisode and chronic schizophrenia. Psychiatry Res. 2019;273:528-536.

[DOI:10.1016/j.psychres.2019.01.051] [PMID]

45. Geinisman Y. Structural synaptic modifications associated with hippocampal LTP and behavioral learning. Cereb Cortex. 2000;10:952-962. [DOI:10.1093/cercor/10.10.952] [PMID]

46. Wei MD. Effects of Electroconvulsive Stimulation on Long-Term Potentiation and Synaptophysin in the Hippocampus of Rats with Depressive Behavior. Journal of ECT. 2012;28:111-117. [DOI:10.1097/YCT.0b013e31824a47ca] [PMID]

47. Karatsoreos I, Butler MP, LeSauter J, Silver R. Androgens Modulate Structure and Function of the Suprachiasmatic Nucleus Brain Clock. Endocrinol. 2011;152:1970-1978. [DOI:10.1210/en.20101398] [PMID] [PMCID]

48. Cooke BM, Woolley CS. Gonadal hormone modulation of dendrites in the mammalian CNS. J Neurobiol. 2005;64:34-46. [DOI:10.1002/neu.20143] [PMID]

49. Pan W, Han S, Kang L, Li S, Du J, Cui H. Effects of dihydrotestosterone on synaptic plasticity of the hippocampus in mild cognitive impairment male SAMP8 mice. Exp Ther Med. 2016;12(3):1455146. [DOI:10.3892/etm.2016.3470] [PMID] [PMCID]

50. Frye CA, Seliga AM. Testosterone increases analgesia, anxiolysis, and cognitive performance of male rats. Cogn Affective Behav Neurosci. 2001;1:371-81. [DOI:10.3758/CABN.1.4.371] [PMID]

51. Isgor C, Sengelaub DR. Effects of neonatal gonadal steroids on adult CA3 pyramidal neuron dendritic morphology and spatial memory in rats. J Neurobiol. 2003;55(2):179-90. [DOI:10.1002/neu.10200] [PMID]

52. Kritzer MF, McLaughlin PJ, Smirlis T, Robinson JK. Gonadectomy impairs T-maze acquisition in adult male rats. Horm Behav. 2001;39(2):167-74. [DOI:10.1006/hbeh.2001.1645] [PMID]

53. Cowan N. What are the differences between longterm, short-term, and working memory? Prog.
Brain Res. 2008;169:323-338.

[DOI:10.1016/S0079-6123(07)00020-9]

54. Olton DS, Papas BC. Spatial memory and hippocampal function. Neuropsychologia. 1979;17:669-682. [DOI:10.1016/00283932(79)90042-3]

55. McConnell SEA, Alla J, Wheat E, Romeo RD, McEwen B, Thornton JE. The role of testicular hormones and luteinizing hormone in spatial memory in adult male rats. Horm Behav. 2012;61:479-486.

[DOI:10.1016/j.yhbeh.2012.01.003] [PMID]

56. Dawson GR, Seabrook GR, Zheng H, Smith DW, Graham S, O'Dowd G. Agerelated cognitive deficits, impaired long-term potentiation and reduction in synaptic marker density in mice lacking the beta-amyloid precursor protein. Neurosci. 1999;90:1-13. [DOI:10.1016/S03064522(98)00410-2]

57. Tarsa L, Goda Y. Synaptophysin regulates activity-dependent synapse formation in cultured hippocampal neurons. Proc Natl Acad Sci USA. 2002;99:1012-6. [DOI:10.1073/pnas.022575999] [PMID] [PMCID]

58. Mulder M, Jansen PJ, Janssen BJ, van de Berg WD, van der Boom H, Havekes LM. Low-density lipoprotein receptor-knockout mice display impaired spatial memory associated with a decreased synaptic density in the hippocampus. Neurobiol Dis. 2004;16:212-9. [DOI:10.1016/j.nbd.2004.01.015] [PMID]

59. Lee W, Moon M, Kim HG, Lee TH, Oh MS. Heat stress-induced memory impairment is associated with neuroinflammation in mice. $\mathrm{J}$ Neuroinflammation. 2015;12:102. [PMID] [PMCID] [DOI:10.1186/s12974-015-0324-6]

60. Zarrouf FA, Artz S, Griffith J, Sirbu C, Kommor $\mathrm{M}$. Testosterone and depression: systematic review and meta-analysis. J Psychiatr Pract. 2009;15:289305. [DOI:10.1097/01.pra.0000358315.88931.fc] [PMID]

61. Veras AB, Nardi AE. The complex relationship between hypogonadism and major depression in a young male. Prog Neuropsychopharmacol Biol Psychiatry. 2010;34(2):421-2.

[DOI:10.1016/j.pnpbp.2009.12.008] [PMID]

62. Cooper MA, Ritchie EC. Testosterone replacement therapy for anxiety. Am J Psychiatry 2000;157 (11):1884. [DOI:10.1176/appi.ajp.157.11.1884] [PMID]

63. Boivin JR, Piekarski DJ, Wahlberg JK, Weibrecht L. Age, sex, and gonadal hormones differently influence anxiety- and depression related behavior during puberty in mice. Psychoneuroendocrinology. 2017;85:78-87. 
[DOI:10.1016/j.psyneuen.2017.08.009] [PMID] [PMCID]

64. McIntyre RS. Calculated bioavailable testosterone levels and depression in middle-aged men.Psychoneuroendocrinology. 2006;31:10291035. [DOI:10.1016/j.psyneuen.2006.06.005] [PMID]

65. McNicholas TA. A novel testosterone gel formulation normalizes androgen levels in hypogonadal men, with improvements in body composition and sexual function. BJU Int. 2003;91:69-74. 410X.2003.04016.x] [PMID]

66. Hui YU, Zhe-yu C. The role of BDNF in depression on the basis of its location in the neural circuitry. Acta Pharmacologica Sinica. 2011;32:311. [DOI:10.1038/aps.2010.184] [PMID] [PMCID]

67. Silva MA, Mattern C, Topic B, Buddenberg TE, Huston JP. Dopaminergic and serotonergic activity in neostriatum and nucleus accumbens enhanced by intranasal administration of testosterone. Eur. Neuropsychopharmacol. 2009;1953-63.

68. Almeida OP, Barclay L. Sex hormones and their impact on dementia and depression: A clinical perspective. Expert Opin Pharmacother. 2001;2: 527-535. [DOI:10.1517/14656566.2.4.527] [PMID]

69. Tronci E, Napolitano F. BDNF over-expression induces striatal serotonin fiber sprouting and increases the susceptibility to L-DOPA-induced dyskinesia in 6-OHDA-lesioned rats. Exp Neurol. 2017;297:73-81. [DOI:10.1016/i.expneurol.2017.07.017] [PMID]

70. Palasz E, Wysock A, Gasiorowska A, Chalimoniuk M, Niewiadomski W, Niewiadomska G. BDNF as a Promising Therapeutic Agent in Parkinson's Disease. Inter J Mol Sci. 2020;21:1-23. [DOI:10.3390/ijms21031170] [PMID] [PMCID]

71. Piantadosi SC, Rocco BR, Lewis DA, Watkins SC, Sibille E. The Role of Dendritic Brain-Derived Neurotrophic Factor Transcripts on Altered Inhibitory Circuitry in Depression. Biol Psychiatry. 2019;85:517-526.

[DOI:10.1016/j.biopsych.2018.09.026] [PMID] [PMCID]

72. Hung YY, Huang YL, Chang C, Kang HY. Deficiency in Androgen Receptor Aggravates the Depressive-Like Behaviors in Chronic Mild Stress Model of Depression. Cells. 2019;8(1021):2-17. [DOI:10.3390/cells8091021] [PMID] [PMCID]
73. Schmidt HD, Duman RS. The role of neurotrophic factors in adult hippocampal neurogenesis, antidepressant treatments and animal models of depressive-like behavior. Behav Pharmacol. 2007;18:391-418.

[DOI:10.1097/FBP.0b013e3282ee2aa8] [PMID]

74. Chen ZY, Jing D, Bath KG, Ieraci A, Khan T, Siao CJ, Herrera DG, Toth M, Yang C, McEwen BS. Genetic variant BDNF (Val66Met) polymorphism alters anxiety-related behavior. Sci. 2006; 314:140-143. [DOI:10.1126/science.1129663] [PMID] [PMCID]

75. Abbas AI, Yadav PN, Yao WD, Arbuckle MI, Grant SG, Caron MG, et al. PSD-95 is essential for hallucinogen and atypical antipsychotic drug actions at serotonin receptors. Journal of Neurosci. 2009;29:7124-7136.

[DOI:10.1523/JNEUROSCI.1090-09.2009] [PMID] [PMCID]

76. Gao C, Tronson NC, Radulovic J. Modulation of behavior by scaffolding proteins of the postsynaptic density. NLM. 2013;105:3-12. [DOI:10.1016/j.nlm.2013.04.014] [PMID] [PMCID]

77. Feyder M, Karlsson RM, Mathur P, Lyman M, Bock R, Momenan R. Association of mouse Dlg4 (PSD-95) gene deletion and human DLG4 gene variation with phenotypes relevant to autism spectrum disorders and Williams' syndrome. Am J Psychiatry. 2010;167:1508-1517.[PMID] [PMCID] [DOI:10.1176/appi.ajp.2010.10040484]

78. Feyissa AM, Chandran A, Stockmeier CA, Karolewicz B. Reduced levels of NR2A and NR2B subunits of NMDA receptor and PSD-95 in the prefrontal cortex in major depression. Prog Neuropsychopharmacol Biol Psychiatry. 2009;33: 70-75. [DOI:10.1016/j.pnpbp.2008.10.005] [PMID] [PMCID]

79. Zhang FX, Sun QJ, Zheng XY, Lin YT, Shang W, Wang AH. Abnormal expression of synaptophysin, SNAP-25, and synaptotagmin 1 in the hippocampus of kainic acid-exposed rats with behavioral deficits. Cell Mol Neurobiol. 2014;34(6):813-24. [DOI:10.1007/s10571-0140068-3] [PMID]

80. Tchantchou F, Tucker LB, Fu AH, Bluett RJ, McCabe JT, Patel S, et al. The fatty acid amide hydrolase inhibitor PF-3845 promotes neuronal survival, attenuates inflammation and improves functional recovery in mice with traumatic brain injury. Neuropharmacol. 2014;85:427-39. [DOI:10.1016/j.neuropharm.2014.06.006] [PMID] [PMCID] 
81. Rapp S, Baader M, Hu M, et al. Differential regulation of synaptic vesicle proteins by antidepressant drugs. Pharmacogenomics J. 2004;4:110-113. [DOI:10.1038/sj.tpj.6500229] [PMID]
82. Xu H, He J, Richardson JS, et al. The response of synaptophysin and microtubule-associated protein 1 to restraint stress in rat hippocampus and its modulation by venlafaxine. J Neurochem. 2004; 91:1380-1388.

\section{How to Cite This Article:}

Salimi Z, Khazaei M R, Moradpour F, Zarei F, Rashidi Z, Ahmadi S M. Effect of Androgen Deprivation by Castration on Cognitive Functions and Behaviors: A Review Study. J Adv Med Biomed Res. 2022; 30 (138) :111

\section{Download citation:}

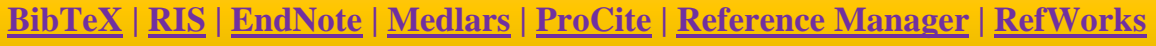

